\title{
ON AN INEQUALITY OF OPIAL AND BEESACK
}

\section{N. LEVINSON ${ }^{1}$}

In further simplifying the proof of an inequality of Opial [3], which had already been simplified by Olech [2], Beesack [1] proved the inequality

$$
\int_{0}^{a}\left|y(x) y^{\prime}(x)\right| d x \leqq \frac{1}{2} a \int_{0}^{a}\left(y^{\prime}(x)\right)^{2} d x
$$

for real $y(x)$ absolutely continuous on $(0, a)$ and with $y(0)=0$. Equality holds only for $y=b x$ where $b$ is a constant.

Here an even simpler proof will be given. Moreover one can take $y(x)$ as complex valued. Clearly

$$
\begin{aligned}
\int_{0}^{a}\left|y^{\prime}(x) y(x)\right| & d x \\
= & \int_{0}^{a}\left|x^{1 / 2} y^{\prime}(x)\right|\left|x^{-1 / 2} \int_{0}^{x} y^{\prime}(\xi) d \xi\right| d x \leqq(A B)^{1 / 2}
\end{aligned}
$$

where

$$
A=\int_{0}^{a} x\left|y^{\prime}(x)\right|^{2} d x
$$

and

$$
B=\int_{0}^{a} x^{-1}\left|\int_{0}^{x} y^{\prime}(\xi) d \xi\right|^{2} d x
$$

by the Schwarz inequality. By the same inequality

$$
\left|\int_{0}^{x} y^{\prime}(\xi) d \xi\right|^{2} \leqq x \int_{0}^{x}\left|y^{\prime}(\xi)\right|^{2} d \xi
$$

with equality only if $y^{\prime}=b$, a constant, almost everywhere. Hence

$$
B \leqq \int_{0}^{a}\left(\int_{0}^{x}\left|y^{\prime}(\xi)\right|^{2} d \xi\right) d x
$$

Received by the editors April 15, 1963.

${ }^{1}$ Supported in part by the Office of Naval Research and the National Science Foundation, NSF GP-149. 
and therefore, inverting the order of integration, we get

$$
B \leqq \int_{0}^{a}\left|y^{\prime}(x)\right|^{2}(a-x) d x
$$

Since

(1), (2) and (3) give

$$
(A B)^{1 / 2} \leqq \frac{1}{2}(A+B)
$$

$$
\int_{0}^{a}\left|y(x) y^{\prime}(x)\right| d x \leqq \frac{1}{2} a \int_{0}^{a}\left|y^{\prime}(x)\right|^{2} d x
$$

which completes the proof.

It has already been seen that inequality occurs unless $y^{\prime}(x)=b$ almost everywhere. This with $y(0)=0$ implies

$$
y(x)=b x .
$$

In this case equality occurs in (4).

\section{REFERENCES}

1. Paul R. Beesack, On an integral inequality of $Z$. Opial, Trans. Amer. Math. Soc. 104 (1962), 470-475.

2. C. Olech, A simple proof of a certain result of $Z$. Opial, Ann. Polon. Math. 8 (1960), 61-63.

3. Z. Opial, Sur une inégalité, Ann. Polon. Math. 8 (1960), 29-32.

MassachusetTs Institute of TeChNology 